\title{
RainPortal - A web portal for providing climate change related precipitation data using SUDPLAN services
}

\author{
Peter Kutschera $^{1}$, Jonas Olsson ${ }^{2}$, and Lars Gidhagen ${ }^{3}$ \\ ${ }^{1}$ Austrian Institute of Technology - AIT, Austria \\ Peter.Kutschera@ait.ac.at \\ ${ }^{2}$ Swedish Meteorological and Hydrological Institute - SMHI, Sweden \\ Jonas.Olsson@smhi.se \\ ${ }^{3}$ Swedish Meteorological and Hydrological Institute - SMHI, Sweden \\ Lars. Gidhagen@smhi.se
}

\begin{abstract}
RainPortal (http://sudplan.ait.ac.at/RainPortalServer) is a web portal that has three main targets: 1) Provide access to scientifically sound data related to some key climate change aspects in Europe, 2) Provide concrete data about climate change related local precipitation changes by using climate model output and 3) Easy usage and incorporation of the provided information into existing planning workflows.
\end{abstract}

Keywords: climate change, mitigation, precipitation, IDF, SUDPLAN, Delta Change

\section{SUDPLAN}

The SUDPLAN (Sustainable Urban Development Planner for Climate Change Adaptation) project ([2] and http://sudplan.eu), which ran from 2010 to 2012, produced a set of services that provide climate change related information, including services to carry out projections of historical local data provided by a user. These projections to the future up to the year 2100 can be done using different assumptions about expected climate changes. These services are based on OGC standards and are accomplished by a decision support system [7] as a frontend. This frontend, called "Scenario Management System" (SMS), targets the whole planning process for cities, including management of resources. While this works well and brings a lot of climate change services to the planner's desk it also adds the requirement to get familiar with a complex tool.

\section{Calculation and usage of IDF data}

IDF is the acronym for Intensity, Duration, and Frequency. Based on measured or calculated high-resolution precipitation data over at least 30 years IDF curves are created using different standardized statistical methods [1]. These curves describe, for

adfa, p. 1, 2011 .

(C) Springer-Verlag Berlin Heidelberg 2011 
a given recurrence frequency (often also named return period) and rain event duration, the maximum precipitation intensity to be expected.

The intensity can be expressed in $\mathrm{mm}$ rain per event duration or in $\mathrm{mm}$ per time step - SUDPLAN services uses mm/h. A typical IDF curve is shown in Fig. 1, featuring for different frequencies $(1,10,100$ years, color coded) the relation between duration (up to 10 hours, to the right) and intensity (up to $100 \mathrm{~mm}$ per hour, to the top). As an example, this curve shows that for a $2 \mathrm{~h}$ rainfall period the strongest intensity to expect every year is about $10 \mathrm{~mm} / \mathrm{h}$, i.e., in total $20 \mathrm{~mm}$ during the event. But over a 10 year period the maximum intensity to expect is $20 \mathrm{~mm} / \mathrm{h}$, and in a 100 year period even more than $30 \mathrm{~mm} / \mathrm{h}$ has to be expected.

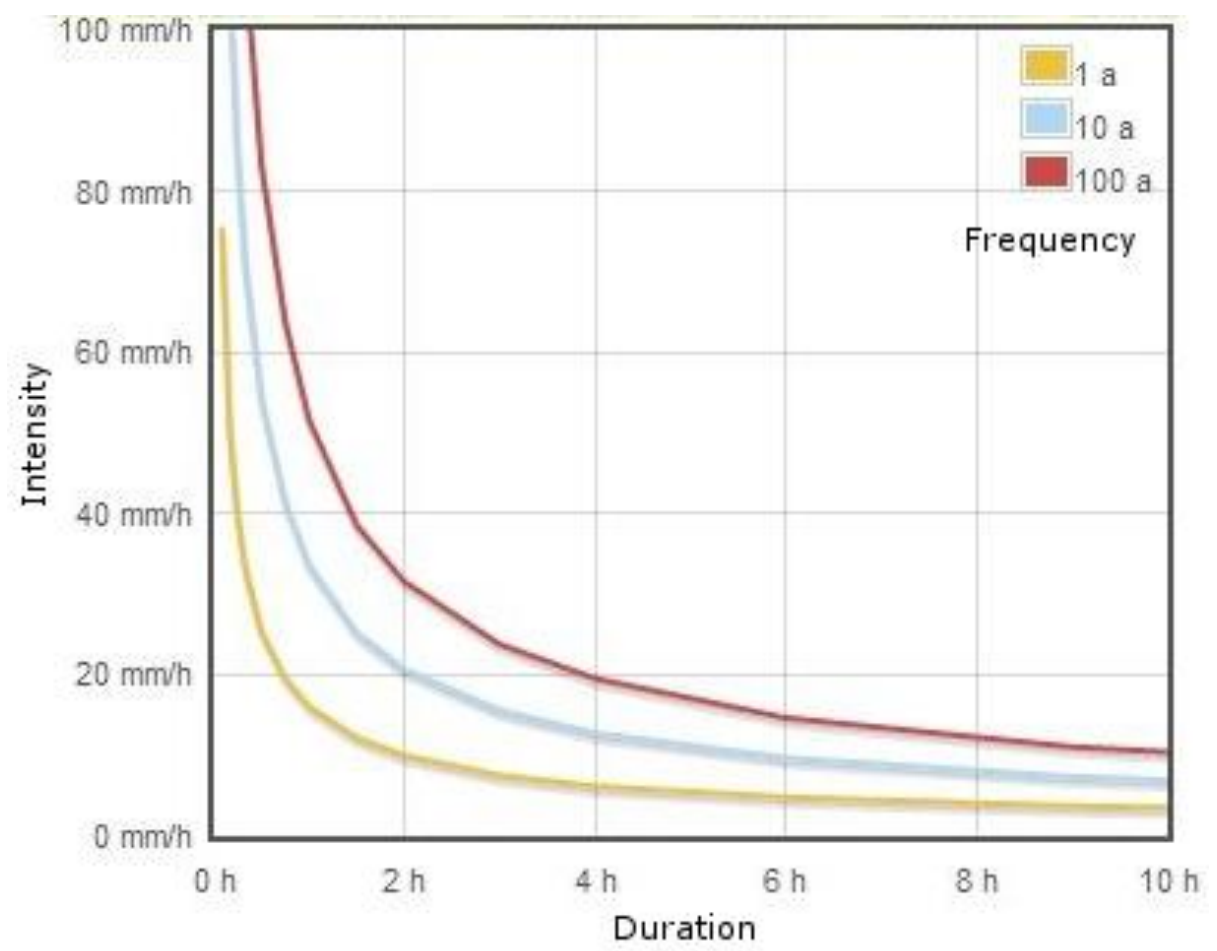

Fig. 1. Typical IDF curves

The most prominent usage of these curves is in the dimensioning of infrastructure and buildings for drainage of rain water from a given area. One of the SUDPLAN pilots $([5,6])$ considered problems related with surface water runoff in the city of Wuppertal.

In general, recommended IDF curves are available in most European countries. In Austria we are in the lucky position that one of our ministries (Ministry of Life; 
http://lebensministerium.at) provides this information free of charge (http://ehyd.gv.at/).

\section{$3 \quad$ Why take climate change into account?}

The actual planning process is based on the knowledge of past conditions. So in the case of planning taking IDF data into account, these actual data are based on statistics about rain conditions over the last 30 years. From this database a sound statement can be given about what type of rain events to expect.

Thus the planning for buildings and infrastructure that should last some 10 up to 100 years is based on historical data. This leads to the question if these historical statistics will still be valid in the future. How much will climate change influence and invalidate the IDF data used? But this question cannot be answered on a global level; local conditions need to be taken into account.

\section{IDF changes from different climate projections}

Future precipitation from global (GCM) and regional climate models (RCM) indicates a large variability. This suggests combining outputs from various models to get a more "robust" estimate of what the future precipitation will be $[9,10]$. Currently the SUDPLAN rainfall downscaling is performed with an ensemble of four future projections from one RCM representing different GCMs and IPCC emission scenarios [10]. Updates with more projections are expected during 2013.

Existing results from RCMs do not accurately reproduce short-term intensity variations (intense short-lived rainfall events) nor small-scale local variations related to, e.g., topography. The Delta Change method used for further downscaling in SUDPLAN is a way to overcome these limitations and provide expected changes of present rainfall characteristics for a specific future 30-year period (up to period 20712100). In the Delta Change method, historically observed rainfall or IDF data is modified to reflect expected future conditions, based on statistical analyses of climate model results. For details about the approach used in SUDPLAN, see further [3].

SUDPLAN's services thus require local historical data to be projected to the future. The usage of local data provides actual local conditions to the result. The influence of future climate change is highly uncertain as there are a lot of different climate models and global emission scenarios available [9, 10]. Today, no one can tell which of them provides the best approximation - or if the future conditions will be outside all the bandwidth of all model results. This is the reason why SUDPLAN services provide results for an increasing list (Table 1) of emission scenarios and global as well as regional climate model combinations. These combinations are referenced as "climate projections" and are described in detail on the SUDPLAN website [8]. Table $\mathbf{2}$ describes the main characteristics of the used emission scenarios. 
Table 1. Actual available combination of emission scenarios and climate models

\begin{tabular}{|l|l|l|}
\hline IPCC scenario & Global Model & Regional Model \\
\hline A1B & ECHAM5 & RCA3 \\
\hline A2 & ECHAM5 & RCA3 \\
\hline A1B & HADCM3 & RCA3 \\
\hline A1B & CCSM3_A1B & RCA3 \\
\hline
\end{tabular}

Table 2. Main assumptions of the used IPCC emission scenarios

\begin{tabular}{|c|c|}
\hline IPCC scenario & Main assumptions \\
\hline A1B & $\begin{array}{l}\text { - Rapid economic growth. } \\
\text { - A global population that reaches } 9 \text { billion in } 2050 \text { and then grad- } \\
\text { ually declines. } \\
\text { - The quick spread of new and efficient technologies. } \\
\text { - A convergent world - income and way of life converge between } \\
\text { regions. Extensive social and cultural interactions worldwide. } \\
\text { - A balanced emphasis on all energy sources. }\end{array}$ \\
\hline $\mathrm{A} 2$ & $\begin{array}{l}\text { - A world of independently operating, self-reliant nations. } \\
\text { - Continuously increasing population. } \\
\text { - Regionally oriented economic development }\end{array}$ \\
\hline
\end{tabular}

Using all these climate projections will result in a broad range of possible results. This range gives the user an impression of the bandwidth of conditions to expect in the future. Subsequently, it is still up to the planner to decide based on his knowledge and experience - but now this is based on scientifically sound estimations of expected future conditions.

\section{$5 \quad$ RainPortal}

In contrast to the complex GUI ([7]) developed in SUDPLAN, RainPortal targets only the projection of precipitation data with the explicit goal of providing a simple user interface. The idea is that a planner already has his tools to do his job in terms of, e.g., hydrologic or hydraulic modeling. Therefore, the RainPortal only provides additional model input information in a format that can easily be used in the established planning process. The first version of the RainPortal allows only the projection of IDF (Intensity-Duration-Frequency) data. 
To use the RainPortal, historical IDF data are needed as a table. Different formats can be used. The 3-column format contains the columns duration (in minutes), frequency (in years) and intensity (either in $\mathrm{mm}$ per event duration or in $\mathrm{mm}$ per hour) in this order (Fig. 2).

\begin{tabular}{|r|r|r|r|}
\hline \multicolumn{1}{|c|}{ A } & \multicolumn{2}{|c|}{ B } & \multicolumn{2}{c|}{ C } \\
\hline 1 & Duration [minutes] & Frequency [years] & Intensity [mm] \\
\hline 2 & 5 & 1 & 6,30 \\
\hline 3 & 10 & 1 & 8,40 \\
\hline 4 & 15 & 1 & 9,90 \\
\hline 5 & 5 & 2 & 8,40 \\
\hline 6 & 10 & 2 & 11,10 \\
\hline
\end{tabular}

Fig. 2. IDF data in 3 column format

Another format is one column per frequency. The units to use are the same as before (Fig. 3).

\begin{tabular}{|r|r|r|r|r|r|r|}
\hline 4 & A & B & C & D & E \\
\hline 1 & & 1 & 2 & 3 & 5 \\
\hline 2 & 5 & 6,3 & 8,4 & 9,5 & 11,1 \\
\hline 3 & 10 & 8,4 & 11,1 & 12,8 & 14,9 \\
\hline 4 & 15 & 9,9 & 13,2 & 15,2 & 17,7 \\
\hline 5 & 20 & 11 & 14,7 & 16,9 & 23,4 \\
\hline 6 & 30 & 12,7 & 17 & 19,6 & 22,7 \\
\hline
\end{tabular}

Fig. 3. IDF data in one column per frequency format

As RainPortal was developed in Austria there exists also the option to use the data format as downloaded from the Austrian ministry.

IDF data are always based on a rain time series of a specific location and are therefore only representative for specific coordinates. These coordinates need to be provided in the WGS84 reference system.

The input data need to represent at least a historical period of 30-years. As the data from the whole time span are used, the year in the center of this period is taken as time reference. This year has also to be specified.

The first step using the RainPortal is loading the IDF curves into the browser (Fig. 4). 


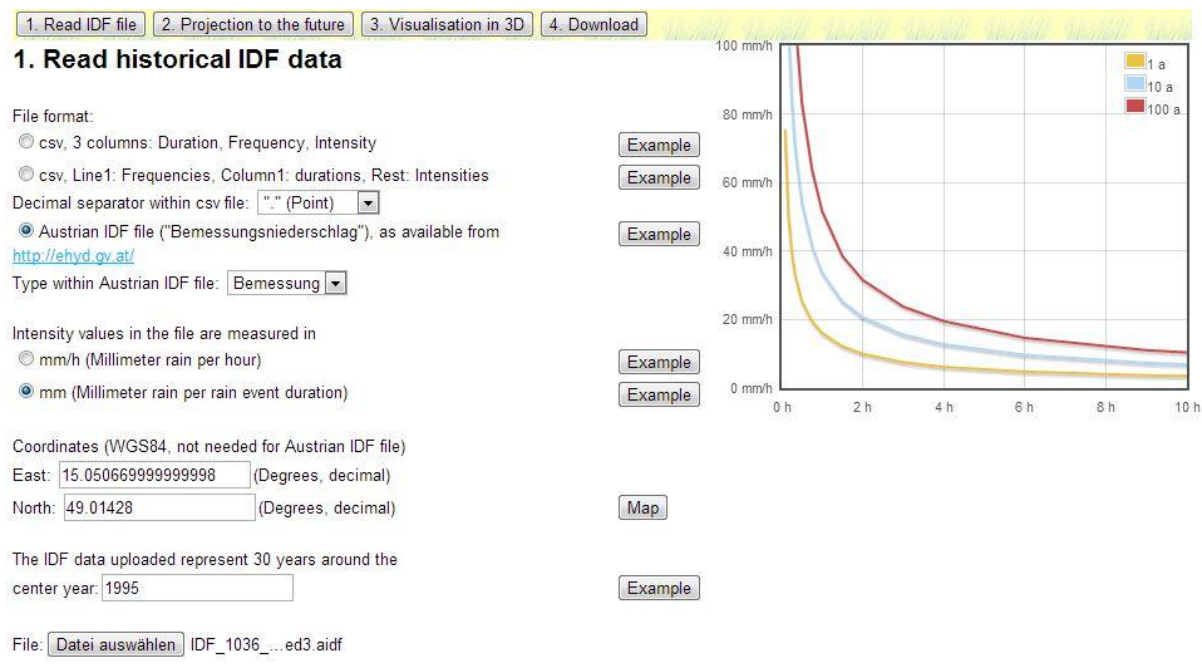

Fig. 4. Loading local IDF curves

The loaded data are shown on the web page as 2D graph and as a table immediately allowing checking.

The second step is the specification of the target period, this is the period used to project the historical data to. Again the center year of a 30-year period has to be specified. The service can perform calculations between years 2011 and 2100, which means a center year in the interval 2026 to 2085.

The service can provide results for different climate projections. But for practical use the option to calculate the minimum and maximum expected values over all climate projections would be most useful.

Pressing the "Start" button will send the input data to the server, triggering the calculations on SHMIs server (Fig. 5), which will take some minutes.

1. Read IDF file 2. Projection to the future 3. Visualisation in 3D 4. Download

2. Projection to the future

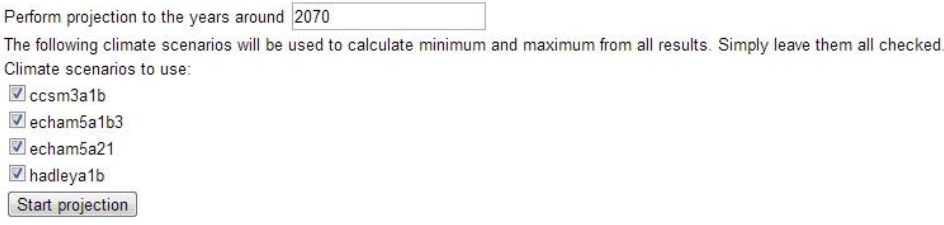

Fig. 5. Requesting projection to the future 
In the third step, the historical data as well as the projections can be examined in a 3D graph (Fig. 6) that can be moved, rotated and zoomed interactively to visualize different aspects. The graph compares historical data (black) with the minimal (green) and maximal (red) values from all calculated climate projections. This example shows a general increase in the intensities to expect.

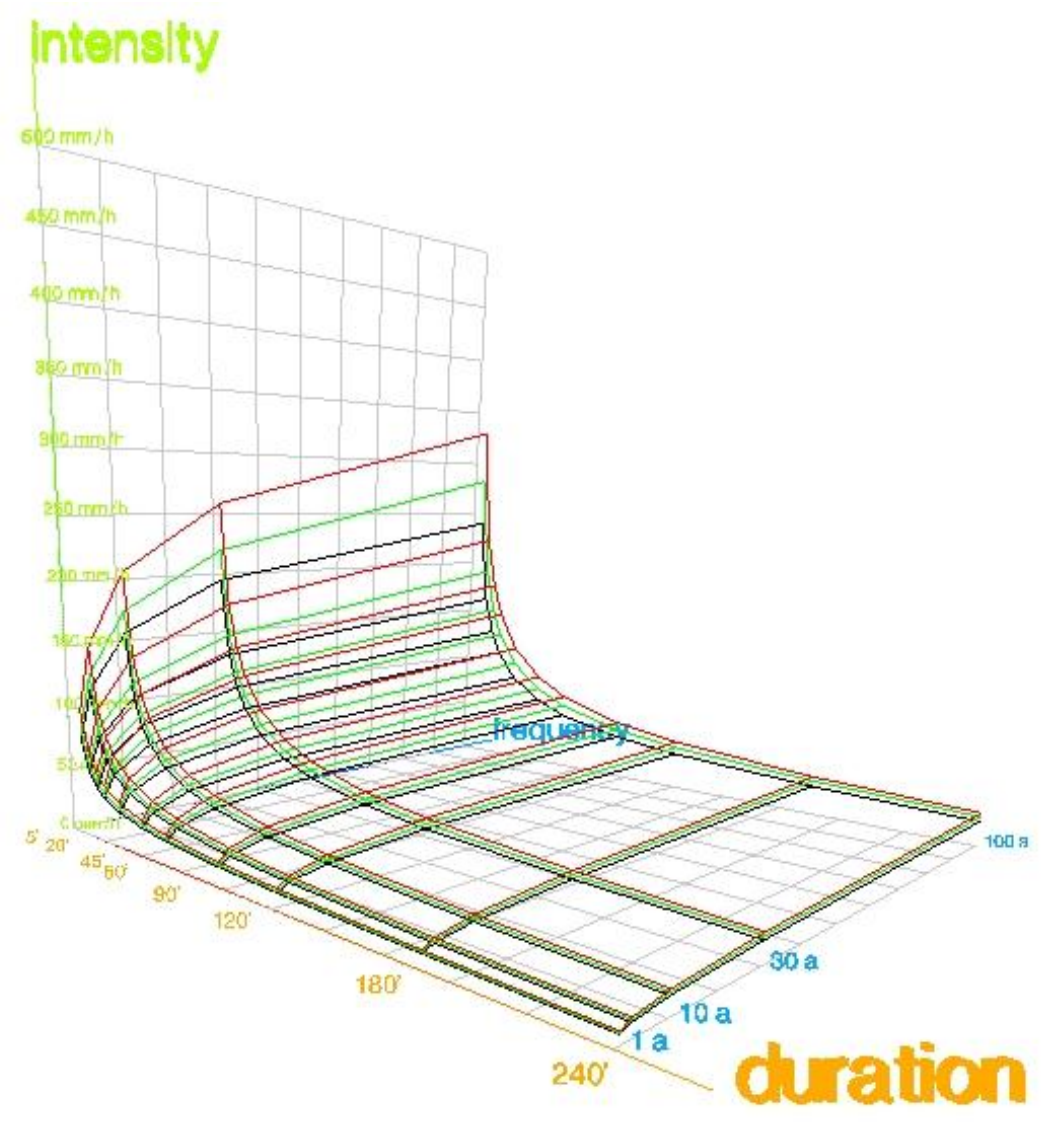

Fig. 6. 3D visualization of results

The same values are available as table (Fig. 7). Additionally, the result for each single climate projection is available. It should be mentioned that it is not clear in advance which climate projection will deliver the maximum values. This is even true within one IDF table, where sometimes one projection delivers the highest intensities for lower frequencies, and another projection for the higher frequencies. 


\begin{tabular}{|c|c|c|c|c|c|c|}
\hline Duration (Minutes) & Scenario & \multicolumn{5}{|c|}{ Frequencies (Years) } \\
\hline & & 1 & 3 & 10 & 30 & 100 \\
\hline & & \multicolumn{5}{|c|}{ Intensities (mm/h) } \\
\hline \multirow[t]{7}{*}{5} & historic, 1995 & 75.60 & 114.0 & 157.2 & 195.6 & 240.0 \\
\hline & $\operatorname{ccsm} 3 a 1 b, 2070$ & 85.10 & 128.6 & 179.1 & 228.9 & 306.8 \\
\hline & minimum & 83.70 & 126.4 & 175.1 & 220.6 & 282.2 \\
\hline & maximum & 98.60 & 148.8 & 205.9 & 258.9 & 329.2 \\
\hline & hadleya1b, 2070 & 98.60 & 148.8 & 205.9 & 258.9 & 329.2 \\
\hline & echam5a21, 2070 & 83.70 & 126.4 & 175.1 & 220.6 & 282.2 \\
\hline & echam5a1b3, 2070 & 93.60 & 141.1 & 194.4 & 240.9 & 291.3 \\
\hline \multirow[t]{7}{*}{10} & historic, 1995 & 50.40 & 76.80 & 106.2 & 132.6 & 162.6 \\
\hline & $\operatorname{ccsm} 3 a 1 b, 2070$ & 56.70 & 86.70 & 121.0 & 155.1 & 207.8 \\
\hline & minimum & 55.80 & 85.20 & 118.3 & 149.5 & 191.2 \\
\hline & maximum & 65.70 & 100.2 & 139.1 & 175.5 & 223.0 \\
\hline & hadleya1b, 2070 & 65.70 & 100.2 & 139.1 & 175.5 & 223.0 \\
\hline & echam5a21, 2070 & 55.80 & 85.20 & 118.3 & 149.5 & 191.2 \\
\hline & echam5a1b3, 2070 & 62.40 & 95.10 & 131.3 & 163.3 & 197.4 \\
\hline 15 & historic, 1995 & 39.60 & 60.80 & 84.00 & 105.6 & 129.2 \\
\hline
\end{tabular}

Fig. 7. Results

The fourth and last step is to download the result. This can be done in different formats to ease the integration of the results into the established planning process.

\section{$6 \quad$ Privacy and data security}

RainPortal is not interested in storing any data about the user. Therefore, the easiest option would be to have the service and all results available to every user without the need for any login. However, this would imply that the results cannot be assigned to a specific user and the uploaded data and results will be visible to everyone. This could raise a problem, as the user might not have the right to publish the data.

Because of this a user management is needed in RainPortal, allowing each user to see only their results. The input data and results will be available to the user for visu- 
alization and download for some days and will be deleted afterwards to avoid resource consumption on the server. RainPortal will only keep some statistics and comments provided by the users.

\section{$7 \quad$ Concluding remarks}

We, the developers of RainPortal, have two goals in mind: 1) The provision of climate change related data to the community and 2) We want to learn about who is this community, how do they use the data, what are their needs and how can we make RainPortal and SUDPLAN as a whole an even better product. So we are asking every user for feedback.

Depending on the success of the RainPortal, future versions might also allow projections of rain timeseries. In contrast to IDF curves, this provides information about changes in overall precipitation volume and changed rain patterns between the yearly seasons.

A key issue is to make the user fully aware of the uncertainties and limitations in the estimated future rain intensities. Local short-term rainfall is notoriously difficult to simulate by climate models, due to the high variability in time and space. In addition, IDF calculations require extreme value analyses that add further uncertainty to the estimated future changes. The final results thus must be considered as very approximate indications of what is likely to happen in the future; which is the probable sign of the change (increase or decrease) and which is the probable magnitude of the change (small or large). In RainPortal, it is strongly recommended to evaluate all available projections to see the range of possible outcomes and on that basis make a qualitative interpretation of the probable change. By combining this with a careful "climate sensitivity analysis" of the system under study (e.g., by identifying rain thresholds at which system response dramatically changes), we hope to provide a useful and sound basis for climate change impact assessment.

\section{$8 \quad$ References}

1. DWA-A 531: Arbeitsblatt DWA-A 531, Starkregen in Abhängigkeit von Wiederkehrzeit und Dauerregen, DWA, 2012

2. Gidhagen, L., Denzer, R., Schlobinski, S., Michel, F., Kutschera, P., Havlik, D. (2010): Sustainable urban Development Planner for Climate Change Adaptation (SUDPLAN). In proceedings of ENVIP'2010 workshop at EnviroInfo2010, Bonn, October 6-8, 2010,CEUR-WS, Vol-679, ISSN 1613-0073, urn:nbn:de:0074-679-9.

3. Olsson, J., Gidhagen, L., Gamerith, V., Gruber, G., Hoppe, H. and Kutschera, P. (2012), Downscaling of Short-Term Precipitation from Regional Climate Models for Sustainable Urban Planning, Sustainability, Volume 4, Issue 5; http://www.mdpi.com/2071$1050 / 4 / 5 / 866$

4. Kutschera, P., Olsson, J., Havlik, D. and Gruber, G. (2012): Future IDF curves for regional planning in Europe - a SUDPLAN result, Geophysical Research Abstracts, EGU General Assembly 2012, http://meetingorganizer.copernicus.org/EGU2012/EGU20129483.pdf 
5. Michel, F., Steffen, D., Schlobinski, S. and Sander, S., (2012). Considering the Impact of Future Climate Change on the Resilience of a City - Surface Run-Off due to Heavy Storm Events in the City of Wuppertal. RealCORP 2012 - Proceedings 17th International Conference on Urban Planning and Regional Development in the Information Society.

6. Sander, S., Hoppe, H., Schlobinski, S., (2011). Integrating climate change in the urban planning process - a case study. Environmental Software Systems. Frameworks of eEnvironment - 9th IFIP WG 5.11 International Symposium, ISESS 2011, Brno, Czech Republic, June 27-29, 2011. DOI 10.1007/978-3-642-22285-6_68.

7. Schlobinski, S., Denzer, R., Hell, T., Güttler, R., 2011. Vision and requirements of scenario-driven environmental decision support systems supporting automation for end-users Environmental Software Systems. Frameworks of eEnvironment - 9th IFIP WG 5.11 International Symposium, ISESS 2011, Brno, Czech Republic, June 27-29, 2011. DOI 10.1007/978-3-642-22285-6_6.

8. Climate scenario descriptions on the SUDPLAN website http://www.sudplan.eu/AboutSUDPLAN/Pan-European-input-data/Climate-scenarios

9. Willems, P., Olsson, J., Arnbjerg-Nielsen, K., Beecham, S., Pathirana, A., Bulow Gregersen, I., Madsen, H. and Nguyen, V-T-V., 2012. Impacts of Climate Change on Rainfall Extremes and Urban Drainage Systems. ISBN: 9781780401256, 238 pp.

10. IPCC, 2007: Climate Change 2007: The Physical Science Basis. Contribution of Working Group I to the Fourth Assessment Report of the Intergovernmental Panel on Climate Change [Solomon, S., D. Qin, M. Manning, Z. Chen, M. Marquis, K.B. Averyt, M.Tignor and H.L. Miller (eds.)]. Cambridge University Press, Cambridge, United Kingdom and New York, NY, USA. 